\title{
Hilar cholangiocarcinoma - the long-term results of radical and palliative treatment
}

\author{
Włodzimierz Otto', Janusz Sierdziński², Justyna Smaga', Krzysztof Dudek' , Krzysztof Zieniewicz'
}

'Departament of General, Transplant and Liver Surgery, University Medical Center, Medical University of Warsaw, Warsaw, Poland

${ }^{2}$ Departament of Medical Informatics and Telemedicine, University Medical Center, Medical University of Warsaw, Warsaw, Poland

Introduction. Hilar cholangiocarcinoma (HC) is a tumor that requires a multidisciplinary approach and treatment. The 3-and 5-year survival rates of HC patients treated with surgery and palliative methods were evaluated in the study. Material and methods. The study covered 368 patients treated between 2000-2014. Of them, 137 patients were categorized for surgery (RT group), and 231 for palliative treatment (PT group). The overall 3- and 5-year survival rates were determined by the log-rank test. The Cox hazard regression model revealed the relative prognostic factors.

Results. The 3 - and 5 -year survival rates accounted for $38 \%$ and $21 \%$ after surgery, but $13 \%$ and 0 after palliative treatment $(p<0.0001)$. Radical tumor resection, negative lymph nodes, and early tumor T stage were the factors conducive to survival. Conclusions. Surgery, if the radical tumor resection is possible, offers a chance for long-term survival. The effects of surgical treatment are of little consequence in the face of poor treatment outcomes of palliative patients, however.

Key words: hilar cholangiocarcinoma, Bismuth-Corlette typing, T-stage typing, hemihepatectomy, negative resection margin

\section{Introduction}

Hilar cholangiocarcinoma $(\mathrm{HC})$ is a tumor of the main lobar extrahepatic bile ducts, distal to segmental bile ducts and proximal to the cystic duct [1,2]. Radical tumor resection that also covers the extrahepatic bile ducts and the unilateral part of the liver provides a chance to cure the disease, but selection of candidates remains challenging [5].

Studies on the results of $\mathrm{HC}$ treatment usually show the effects of surgery or the effects of palliative treatment in the particular groups of patients [3-6]. Few studies focus on an analysis of all patients admitted and treated at a multidisciplinary department of a single institution over a long period of time [7]. This prompted the presentation of own experience in the management of $\mathrm{HC}$ patients undergoing radical surgery and palliative care in the multidisciplinary HPB department of Medical University of Warsaw. The 3- and 5-year cumulative overall survival rates and factors conducive to the survival of the patients were the end-points of this study.

\section{Material and methods}

The study covered a cohort of 368 patients (F 178, M 190, median age 58.3, range 23-94, SD +/-13.9 years) with Klatskin's tumors, who were transferred from public hospitals in the period of 2000-2014. Of them, 65\% had already undergone bile duct stenting. Tumors were evaluated for radical surgery by using the T-stage classifications as assessed using CT, MRIch and USG imagings [8-11, 13]. The presence of adenocarcinoma

\section{How to cite:}

Otto W, Sierdziński J, Smaga J, Dudek K, Zieniewicz K. Hilar cholangiocarcinoma - the long-term results of radical and palliative treatment. NOWOTWORY J Oncol $2021 ; 71: 348-356$. 
was confirmed in each case by the pathologist based on tissue biopsies and/or tissue material removed during surgery. The TNM clinical stage (UICC) was determined in patients who underwent surgery.

\section{Patients qualified for radical surgery}

The group consisted of 137 (37.2\%) patients (F 63, M 74, median age 57.3 years, (range 23-78, SD +/-12.2). 87 patients ( $F 37, M$ 50 , median age 57.3 years) were already prosthetized before the transfer. The tumor was of stage Bismuth-Corlette II, IIIA, and IIIB in 6, 81 and 50 patients, respectively. Tumor clinical stage of T1 was determined for 29 patients and T2 for 108 . The extended right hemihepatectomy included the right liver lobe, the inferior part of segment IV, the hilar plate, and the entire caudate lobe. The extended left hemihepatectomy included the left liver lobe, the right paramedian sector of the hilar plate, and most of the caudate lobe. Six tumors of the Bismuth II type were excised locally. Lymph nodes of the celiac axis, common hepatic artery, and all lymphatic structures in the hepatoduodenal ligament were coupled with complete resection of the extrahepatic bile duct in all of the patients. A frozen-section analysis of the margins was used to guide resection. The biliary tract continuity was restored by the anastomosis of the remaining hepatic duct to the Roux-Y jejunal loop. The postoperative course was uncomplicated in 78 patients (57\%). 14 patients (10.2\%) died due to postoperative complications. The result of R0, R1, and R2 tumor resection was obtained in 100 (73\%), 24 (17.5\%), and 13 (9.5\%) of the patients, respectively. The extent of carcinoma infiltration within the removed tissues was described in details by the pathologist in every patient. The TNM clinical stage was determined as T1N0M0 in 29 patients, T2N0M0 in 58 patients, and T3N1M0 in 50 patients. Adjuvant chemotherapy was applied only to 37 patients undergoing $\mathrm{R} 1 / \mathrm{R} 2$ tumor resection. The details are presented in table I.

\section{Patients having tumors clearly unresectable (Palliative A)}

The group consisted of 210 patients (57.3\%, F 101, M 109, median age 59.9, range $26-94$, SD +/-11.0 years). Of them, $66 \%$ were already prosthetized before the transfer. The tumor was of stage Bismuth-Corlette II, IIIB and IV in 5, 25, and 180 patients, respectively. Radiologic tests indicated clearly the tumor unresectability (clinical T3 stage). No distant metastases were found in any of the patients, however. Infiltration of the bile duct by cholangiocarcinoma was confirmed by the pathologist in specimens obtained by biopsy or biliary brushing during ERCP. Clinical advances of the tumor were not possible to be calculated (TxNxMO)

\section{Patients having unresectable tumors, as found during laparotomy (Palliative B)}

In 21 patients (5.7\%, F 14, M 7, median age 59.2, range 48-76, SD +/-14.2 years) imaging studies indicated the possibility of radical operation. Tumor was of stage Bismuth-Corlette IIIA in 8 patients, and IIIB in 13, and the clinical stage T2 was determined by radiologic tests. The operative exploration allowed to recognize excessive tumor involvement (T3 stage) and its unresectability. The reason for withdrawing them from radical surgery was tumor involvement of the main trunk of the portal vein in 14 cases, involvement of the common hepatic artery in 4, and the tumor's extensive spread to the contralateral duct in 7 patients. Operations ended after collection of tissue specimens. All patients were treated by endoscopic stenting over the postoperative period. Postoperative complications were frequent. Pathologic diagnosis was obtained by examination of the specimens taken during the explorative operation. Perineural invasion and lymph nodes invasion of the tumor were present in all patients. No distant metastases were found. The TNM stage of T4N1M0 was determined in all patients.

\section{Palliative care modalities}

The group of palliative patients consisted of 231 patients in total (63\%, F 115, M 116, median age 58.9, range 26-94, SD $+/-13.6$ years). Endoscopic stenting of the bile duct tree was applied to all 231 patients. Depending on individual indications, plastic stents or different types of SEMSs prosthesis were inserted to provide effective bile drainage. The procedure was effective in 199 patients (86.1\% out of 231 in this group), and uncomplicated in 145 (62.7\%). 13 patients (5.6\%) died due to a failure in the procedure or serious biliary complications. In the follow-up period, plastic stents were usually changed every 2-4 months. Metal SEMS prostheses were targeted for permanent decompression of the biliary tree, however, more than 50\% had intermittent cholangitis along with the treatment. Early complications also included infection, bleeding, pancreatitis, and often occlusion caused by sludge in both types of stents. Dislodgment happened in 14\% and in 5\% of the fully and partially covered SEMS prostheses. 76 of the patients (33\%) received chemotherapy by using gemcitabine and platinum-based regimens, according to the oncologist's order. The details are presented in table II.

\section{Statistical analysis}

Data were summarized with follow-up to December 31, 2019. Cumulative overall patient survival rates at 3 and 5 years were determined as percent of patients and calculated by the Kaplan-Meier method using the log-rank test with adjustment for the type of treatment. The Chi-square test was used to analyze categorical data. The Cox proportional hazard regression model was used to assess the relative prognostic factors influence on patient survival. Values of $p<0.05$ were considered significant.

\section{Results}

14 out of 137 patients from the RT group (10.2\%), and 13 out of 231 patients from the PT group (5.6\%), died during treatment due to serious complications ( $p>0.71)$. The median 
Table I. Demographic data, tumor features, procedures used and complications in patients treated by surgery

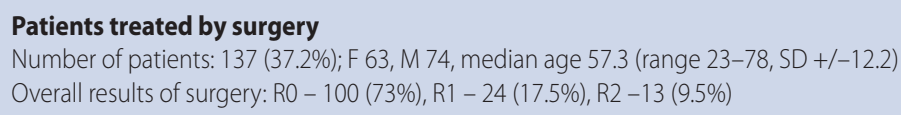

Number of patients: 137 (37.2\%); F 63, M 74, median age 57.3 (range 23-78, SD +/-12.2)

Overall results of surgery: R0 - 100 (73\%), R1 - 24 (17.5\%), R2 -13 (9.5\%)

\begin{tabular}{|c|c|c|c|c|c|c|}
\hline \multicolumn{3}{|c|}{ Detail description of variables } & & $\begin{array}{l}\text { Number } \\
\text { of patients }\end{array}$ & Female & Male \\
\hline \multirow{2}{*}{\multicolumn{3}{|c|}{ endoscopic prosthesis procedure prior to referral }} & yes & $87(63 \%)$ & 37 & 50 \\
\hline & & & no & 50 & 26 & 24 \\
\hline \multicolumn{7}{|c|}{ Right extended hemihepatectomy for Bismuth-Corlette type IIIA } \\
\hline effects of surgery & T-stage & TNM class. & No. of pts. & 97 & 46 & 51 \\
\hline \multirow{3}{*}{ RO } & $\mathrm{T} 1$ & T1NOMO & 16 & \multirow{3}{*}{73} & \multirow{3}{*}{36} & \multirow{3}{*}{37} \\
\hline & \multirow{2}{*}{$\mathrm{T} 2$} & T2NOMO & 50 & & & \\
\hline & & T3N1M0 & 7 & & & \\
\hline \multirow{3}{*}{ R1 } & \multirow{2}{*}{$\mathrm{T} 1$} & T1NOMO & \multirow{2}{*}{ none } & \multirow{3}{*}{16} & \multirow{3}{*}{6} & \multirow{3}{*}{10} \\
\hline & & T2NOMO & & & & \\
\hline & $\mathrm{T} 2$ & T3N1M0 & 16 & & & \\
\hline \multirow{3}{*}{ R2 } & \multirow{2}{*}{$\mathrm{T} 1$} & T1NOMO & & \multirow{3}{*}{8} & \multirow{3}{*}{4} & \multirow{3}{*}{4} \\
\hline & & T2NOMO & none & & & \\
\hline & $\mathrm{T} 2$ & T3N1M0 & 8 & & & \\
\hline
\end{tabular}

Left extended hemihepatectomy for Bismuth-Corlette type IIIB

\begin{tabular}{|c|c|c|c|c|c|c|}
\hline effects of surgery & T-stage & TNM class. & No. of pts. & 34 & 12 & 22 \\
\hline \multirow{3}{*}{ RO } & $\mathrm{T} 1$ & T1N0M0 & 13 & \multirow{3}{*}{21} & \multirow{3}{*}{7} & \multirow{3}{*}{24} \\
\hline & \multirow{2}{*}{$\mathrm{T} 2$} & T2NOMO & 5 & & & \\
\hline & & T3N1M0 & 3 & & & \\
\hline \multirow{3}{*}{ R1 } & \multirow{2}{*}{$\mathrm{T} 1$} & T1N0M0 & \multirow{2}{*}{ none } & \multirow{3}{*}{8} & \multirow{3}{*}{4} & \multirow{3}{*}{4} \\
\hline & & T2N0MO & & & & \\
\hline & $\mathrm{T} 2$ & T3N1M0 & 8 & & & \\
\hline \multirow{3}{*}{$\mathrm{R} 2$} & \multirow{2}{*}{$\mathrm{T} 1$} & T1NOMO & \multirow{2}{*}{ none } & & \multirow{3}{*}{1} & \multirow{3}{*}{4} \\
\hline & & T2NOMO & & 5 & & \\
\hline & $\mathrm{T} 2$ & T3N1M0 & 5 & & & \\
\hline
\end{tabular}

Local tumor resection for Bismuth-Corlette type II

\begin{tabular}{|c|c|c|c|c|c|c|}
\hline effects of surgery & T-stage & TNM class. & No. of pts. & 6 & 3 & 3 \\
\hline RO & $\mathrm{T} 1$ & T1N0M0 & 6 & 6 & 3 & 3 \\
\hline \multicolumn{7}{|c|}{ Results of pathologic examination } \\
\hline \multirow{2}{*}{ lymph nodes infiltration } & & & yes & 50 & 19 & 31 \\
\hline & & & no & 87 & 44 & 43 \\
\hline \multirow{2}{*}{ liver parenchyma infiltration } & & & yes & 64 & 31 & 33 \\
\hline & & & no & 73 & 32 & 42 \\
\hline \multirow{2}{*}{ perineural invasion } & & & yes & 33 & 13 & 20 \\
\hline & & & no & 104 & 50 & 54 \\
\hline \multicolumn{7}{|c|}{ Postoperative course and complications (Clavien-Dindo scale) } \\
\hline \multicolumn{3}{|l|}{ unomplicated } & & $78(57 \%)$ & 40 & 38 \\
\hline \multicolumn{3}{|l|}{ grade I } & & 12 & 2 & 10 \\
\hline \multicolumn{3}{|l|}{ grade $\|$} & & 15 & 9 & 6 \\
\hline \multicolumn{3}{|l|}{ grade III } & & 5 & 0 & 5 \\
\hline \multicolumn{3}{|l|}{ grade IV } & & 13 & 5 & 8 \\
\hline \multicolumn{3}{|l|}{ grade V (death) } & & $14(10.2 \%)$ & 7 & 7 \\
\hline \multicolumn{4}{|c|}{ Adjuvant chemotherapy ( all R1 and R2 patients) } & $37(27.7 \%)$ & 15 & 22 \\
\hline
\end{tabular}


Table II. Demographic data, tumor features, procedures used and complications in patients treated by palliative methods

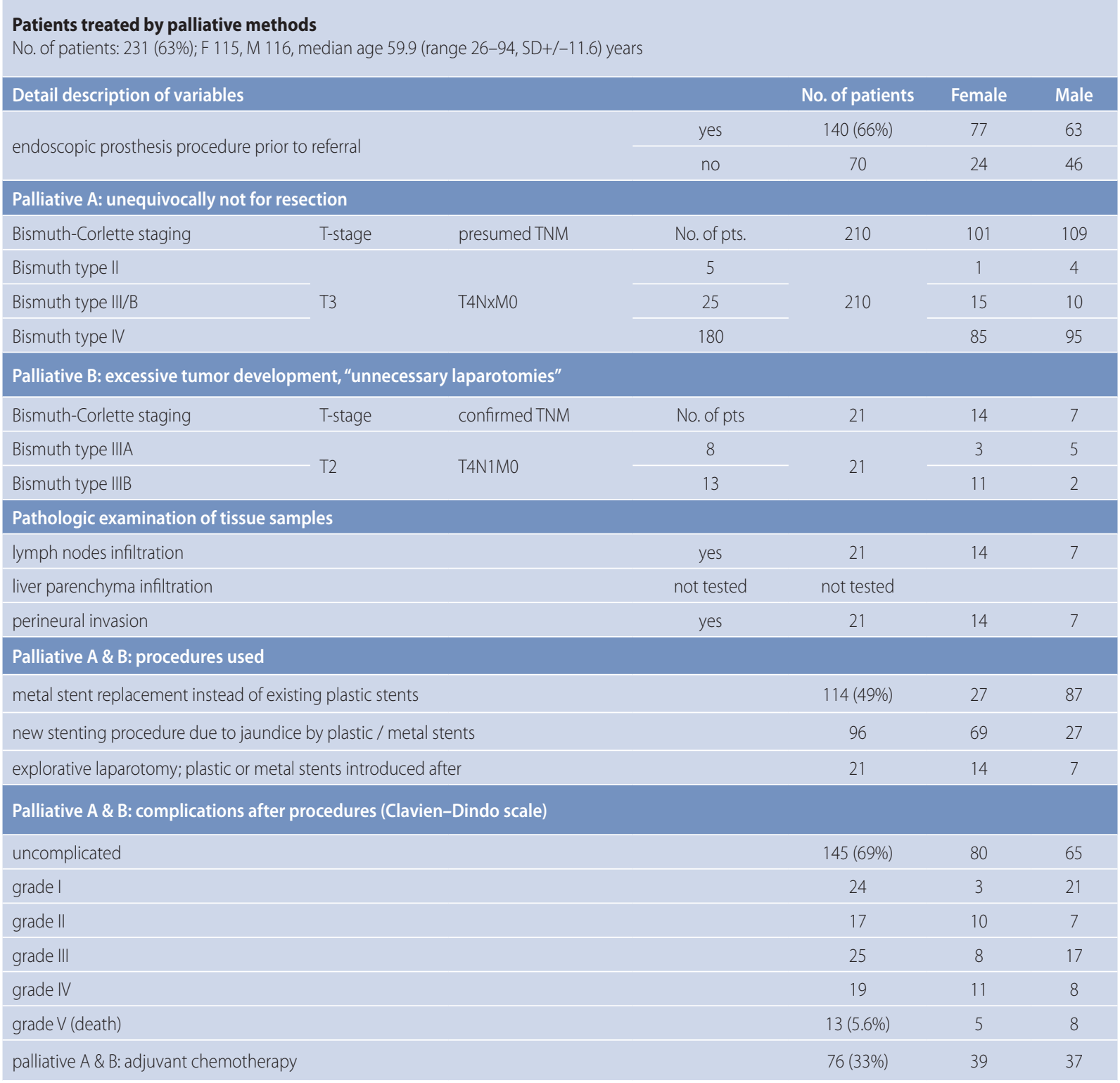

survival time for the 368 patients participating in the study was 15.3 months, whereas the cumulative survival rates of 3- and 5 -years were $27 \%$ and $11 \%$, respectively. The median survival time of patients treated by surgery was 19.5 months (including patients with RO, R1, R2 resections of 24, 17, and 14 months, respectively), and for patients treated by palliative methods it was 13 months $(p<0.001)$. Statistical values are shown in table III.

\section{The effect of $R 0$ resection}

The 3-and 5-year cumulative survival rates in the 137 patients treated by surgery were $38 \%$ and $21 \%$, whereas in the 231 patients treated with palliative methods it was $13 \%$ and 0 , respectively (log-rank test $-5.01, p<0.0001)$. On the other hand, in the 100 patients undergoing R0 resection it was 50\% and $30 \%$, but in the 37 patients undergoing R1/R2 resection it was $20.5 \%$ and 0 , respectively (log-rank test $-3.15, p<0.002$ ). No significant differences in the 3-and 5-year survival rates were found between patients undergoing $\mathrm{R} 1$ resection (survival rates accounting for $21 \%$ and $0 \%$ ) and $\mathrm{R} 2$ resection (survival rates accounting for $11.5 \%$ and 0 ), (log-rank test -0.60 , p > 0.54; in between patients undergoing R1/R2 resection and those treated with palliative methods (log-rank test -0.65 , p > 0.58); in between the palliative patients who received adjuvant chemotherapy and those who did not receive it (log-rank - 0.87, p > 0.28) (fig. 1).

\section{The effect of T-stage}

Patients categorized by T-stage classification were eligible for tumor resection while being in the $\mathrm{T} 1$ or $\mathrm{T} 2$ tumor stage. Resection R0 was achieved in 35 patients with $T 1$ and 65 patients with $T 2$ tumors, while $R 1$ and $R 2$ resection was achieved in 24 
Table III. Analysis of patient survival based on treatment modality

\begin{tabular}{|c|c|c|c|c|c|c|c|}
\hline \multirow[t]{2}{*}{$\begin{array}{l}\text { Dependent } \\
\text { variables } \\
\text { Survival time }\end{array}$} & \multicolumn{3}{|c|}{$\begin{array}{c}\text { Value ' } z \text { ' for multiple comparisons; } \\
\text { independent variable (grouping): } \\
\text { treatment modality } \\
\text { Kruskal-Wallis test: } \\
\mathrm{H}(2, \mathrm{~N}=368)-31.27 \mathrm{p}<0.0001\end{array}$} & $\begin{array}{c}\text { Dependent } \\
\text { variable } \\
\text { Survival time }\end{array}$ & \multicolumn{3}{|c|}{$\begin{array}{l}\text { P value for multiple comparisons; } \\
\text { independent variable (grouping): } \\
\text { treatment modality } \\
\text { Kruskal-Wallis test: } \\
\mathrm{H}(2, \mathrm{~N}=368)-31.27 \mathrm{p}<0.0001\end{array}$} \\
\hline & RO & $\mathrm{R} 1$ + R2 & PT & & RO & $\mathrm{R} 1+\mathrm{R} 2$ & PT \\
\hline RO & & & 2.81 & RO & & 0.014 & 0.0001 \\
\hline$R 1+R 2$ & 2.81 & & & $\mathrm{R} 1+\mathrm{R} 2$ & 0.014 & & 1.00 \\
\hline PT & 5.56 & 0.85 & & PT & 0.0001 & 1.00 & \\
\hline
\end{tabular}
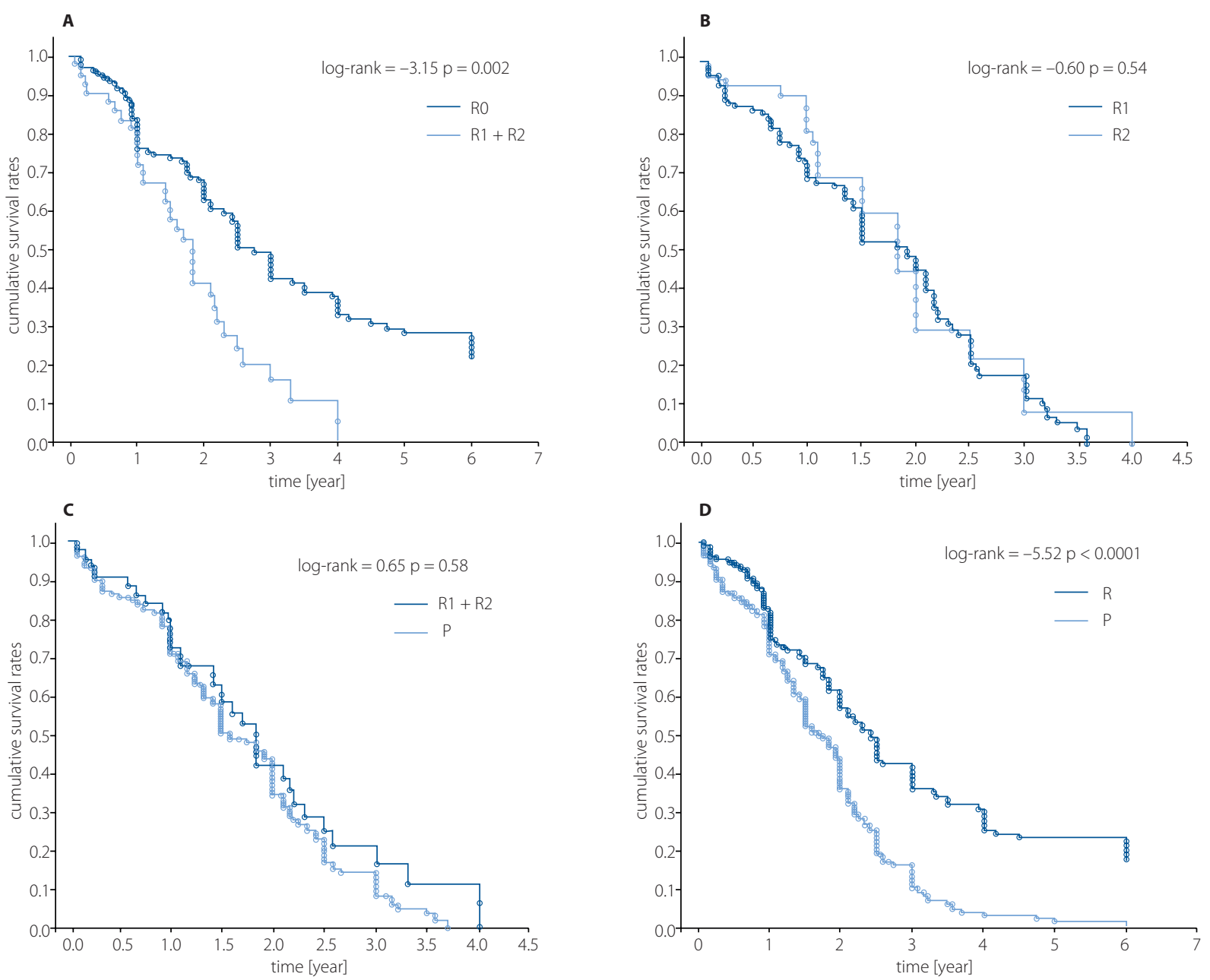

Figure 1. Kaplan-Meier survival estimate of patients with curatively intent surgeries and with patients treated with palliative methods. A. Survival time differed significantly between R0 and R1/R2 resection; B. No significant difference in survival time was found between resection R1 and R2; C.No significant difference in survival time was found between resection R1/R2 and palliative treatment; $\mathbf{D}$. Survival time differed significantly between R0 resection and palliative treatment

and 13 patients, all with T2 tumors. The median survival time of patients with T1 tumors was 29.1 months and of patients with 12 tumors - 15.5 months. On the other hand, all patients with T3 tumors were suitable only for palliative treatment, with a median survival time of 13 months. The median survival of all 368 patients that were categorized by T-stage was 14.7 months. Further analysis by multiple comparisons showed that the survival time of patients with stage $\mathrm{T1}$ tumors was significantly longer than those with stage $T 2(p<0.015)$, and T3 $(p<0.002)$. No significant difference was found in the survival time of patients with T2 and T3 stage tumors ( $<<1.0)$, (tab. IV). The T-stage of a tumor corresponded clearly to its local growth and spread, as was confirmed by the pathologist in post-operative specimens that had been removed. Only patients determined as T1-stage possessed tumors in the early stage of development (T1NOMO), whereas in the 2 patients, tumors 
Table IV. Analysis of patient survival based on T-stage classification

\begin{tabular}{|c|c|c|c|c|c|c|c|}
\hline \multirow[t]{2}{*}{$\begin{array}{l}\text { Dependent } \\
\text { variables } \\
\text { Survival time }\end{array}$} & \multicolumn{3}{|c|}{$\begin{array}{l}\text { Value ' } z \text { ' for multiple comparisons; } \\
\text { independent variable (grouping): } \\
\text { T-staging system } \\
\text { Kruskal-Wallis test: } \\
H(3, N=368)-18.33 p=0.0004\end{array}$} & $\begin{array}{l}\text { Dependent } \\
\text { variable } \\
\text { Survival time }\end{array}$ & \multicolumn{3}{|c|}{$\begin{array}{l}\text { P value for multiple comparisons; } \\
\text { independent variable (grouping): } \\
\text { T-staging system } \\
\text { Kruskal-Wallis test: } \\
\mathrm{H}(3, \mathrm{~N}=368)-18.33 \mathrm{p}=0.0004\end{array}$} \\
\hline & T1-stage & T2-stage & T3-satge & & T1-stage & T2-stage & T3-stage \\
\hline T1-stage & & 3.02 & 3.54 & T1-stage & & 0.015 & 0.002 \\
\hline T2-stage & 3.02 & & 0.55 & T2-stage & 0.015 & & 1.00 \\
\hline T3-stage & 3.54 & 0.55 & & T3-stage & 0.002 & 1.00 & \\
\hline
\end{tabular}

Table V. Results of multivariate analysis using the Cox regression model for factors conducive to patient survival

\begin{tabular}{|lcc}
\hline Parameter & Chi-square & Pr $>$ ChiSq \\
\hline tumor resection R0 vs. R1/R2 & 14.79 & $<0.001$ \\
\hline lymph nodes negative vs. involved & 21.08 & $<0.001$ \\
\hline tumorT1-stage vs. T2/T3 & 5.21 & $<.27$ \\
\hline
\end{tabular}

were more advanced (T2N0 and T3N1). Their survival time was shorter, and unfortunately, it did not differ significantly from the survival of palliative patients treated. The results indicate the dependence of long-term outcomes from the clinical T-stage of tumor development, but also lymph node involvement in the cancer mass.

\section{Prognostic factors}

The analysis revealed that Ro tumor resection, the negative lymph nodes, and the tumor at T1-stage, are factors favorable for patients'survival $(p<0.001$ and $0<0.02)$. Consequently, the less advanced the tumor is, the easier it is to achieve radical resection and the better the long-term result (tab. V). The differences in the cumulative survival rates that would arise from the patients'sex, age, and postoperative complications or differences in the operative or endoscopic treatment modality were found to be statistically not significant.

\section{Discussion}

The study demonstrated that R0 tumor resection offers a chance at long-term survival, however the procedure can be applied in only circa 30\% of cases. In such patients, the 3- and 5-year cumulative survival rates were $50 \%$ and $30 \%$, respectively, with a perioperative mortality of $10.2 \%$. Although the resection was challenging in numerous cases, the postoperative complications were not frequent, and the postoperative mortality accounted for $10.2 \%$, since only 14 patients died. The results corresponded to experience presented i.e. by van Gulik et al., Zhang et al., Baton, et al. and some others [19-24].

The study showed that the T-staging system served as a good indicator for postoperative prognosis. The oncologic radicalism has been achieved following the principles of liver surgery that are generally known and accepted $[2,7,11-16$, $21,22]$. A particular strength of the present study was that the diagnosis of hilum carcinoma was confirmed in all patients by positive histology or cytology. Therefore, the clinical stage of the patients could be classified according to UICC/AJCC system $[7,16,18]$. The pathologic examination of the operative specimens showed that all T1-stage patients should be classified as T1NOMO, whereas T2-stage patients as at least T2NOMO, but also as T2N1M0. This indicated a close correlation between the T-staging system, the multifactorial pTNM staging and the clinical stage of tumor development, which is obvious and confirmed by years of experience [13-17, 23-25]. Therefore, the median survival time of patients with $\mathrm{T} 1 \mathrm{tumors}$ was significantly longer than of patients with $T 2$ tumors, regardless that the resection was $\mathrm{R} 0$ in each case $(p<0.015)$. No significant difference was found, however, in the median survival time of patients with $\mathrm{T} 2$ tumors undergoing palliative resection and the T3 tumors, treated with palliative methods ( $p>1.0$ ). In fact, all patients who underwent tumor resection, limited to the state of R1 and R2, were classified as T3N1M0 by the pathologist. The above data has suggested that patients without lymph node involvement have a better survival chance. Actually, the negative lymph nodes were found as one of the factors conductive to the survival of the patient in the multivariate analysis by using the Cox regression model in this study. The literature provides conflicting results regarding the association of lymph node status on survival, with some authors showing a clear effect $[14,22]$ and some showing none $[7,26]$. Nonetheless, our results indicate the dependence of long-term outcomes from the clinical T-stage of tumor development, but also the lymph node involvement in the cancer mass. Consequently, the less advanced the tumor, the easier it is to achieve radical resection and the better the long-term outcome $[4,7,13-17]$.

The effectiveness of the preoperative assessment has proven insufficient in over $15 \%$ of patients. In fact, they had an advanced cancer, which was confirmed during explorative 
laparotomy or the surgery had to be limited to the stage R1/ R2 (all T4N1M0). The problem is generally known as "unnecessary laparotomies", and is mentioned as one of the causes of poor treatment results in $\mathrm{HC}$ patients. However, the study by Jarnagin et al. [7], and Zhang et al. [20] reveal longer survival rates after palliative tumor resection. Also, Baton et al. [21] found that R1 hepatic resection with no other risk factors can offer better long-term survival. On the other hand, in a study by Seyama et al. [22], no difference in survival was seen between R0 resection with a margin $<5 \mathrm{~mm}$ and $\mathrm{R} 1$ resection. Indeed, the 3- and 5-year cumulative survival rates were longer in R1 than R2 of patients, but, the difference was statistically irrelevant (log-rank test $-0.6, p>0.54$ ). Moreover, survival rates of patients after a palliative R1/R2 resection and patients treated with endoscopic methods were statistically also irrelevant (log-rank test $-0.65, p>0.58$ ). It was exactly one month longer than in patients treated with endoscopic palliative modalities. Stenting procedures were successful in $86.1 \%$ of unresectable patients. SEMS prostheses were generally preferred to plastic stents, however, in most advanced cases, plastic stents were considered sufficient. Complications were not numerous and hospital stay mortality concerned $5.6 \%$ of patients. Others estimate the success rate at $55 \%$ to $90 \%$ of the adequate endoscopic drainage for hilar tumors, also indicating a higher risk of cholangitis in such patients [27-29]. Surprisingly, and contrary to studies demonstrating the clear advantage of gemcitabine/ cisplatin-based chemotherapy, we found no significant differences in the survival of patients who were treated this way (log-rank - 0.87, p > 0.28) [24-26]. The results quoted above correspond to some other reports $[7,11,18,19,30]$.

The positive effects of surgical treatment are obscured by the vast majority of patients presented with advanced locoregional disease. This is clearly demonstrated by the poor overall survival of the whole population that is accounted in months, despite the efforts and significant achievements in the treatment of non surgical patients $[1,4,7,8,15,22,23]$. The analysis showed that 231 patients were in the T3-stage of the tumor, denoting unilateral or contralateral portal vein involvement and homolateral or contralateral hepatic atrophy, that corresponded to clinical stage T4NxM0, according to UICC/AJCC classification [7, 16, 24-26]. The main goals for the palliation of patients with advanced hilar cholangiocarcinoma are decompression of the biliary system and control of tumor growth by chemo- radiotherapy [5, 11, 27, 28]. However, adjuvant treatment (radiotherapy, chemotherapy or a combination of both procedures) for locally advanced tumors, and especially for tumors with distant metastases, seems not to influence the oncological outcome in terms of disease-free survival and overall survival [7, 14, 22, 24]. Our modest results achieved in patients with palliative methods seem to confirm this experience. This is one of the most challenging malignancies of the liver and the biliary system. The overall survival of patients suffering from hilar chiolangiocarcinoma is poor, in spite of progress in modern diagnostics and methods of treatment $[7,8,15,16$, $18,22]$. The biological behavior of the tumor and its strategic location are the principal reasons for this state of affairs.

In Polish literature, there are no analyses of multicentre clinical studies concerning the diagnosis and treatment of the Klatskin tumor. Reports on the outcomes after radical and palliative surgical treatment are particularly lacking. Peripheral hepatico-jejunostomy is proposed by some authors as an alternative palliative surgical method of treatment in advanced cases [31, 32]. Most seem to rely on the implantation of plastic and metal stents, which in practice, was primarily used for palliation of the patients discussed in our study [33, 34]. Overall, the treatment results are poor; 5-year survival is defined as about $1 \%$ in all treated for CCA patients and up to $20 \%$, if it is possible to treat patients by radical surgery [31-33]. The effectiveness of chemotherapy in the treatment of hilar carcinoma is low, however, it is proposed as an adjuvant or palliative in selected patients. Constant control observations, biochemical and imaging tests are recommended, depending on the clinical course $[35,36]$.

Polish experiences differ somewhat from the trends presented in many contemporary reports. Tumor resection is still the only potentially curative option for Klatskin tumor patients, although only a small percentage of patients are eligible for surgery. The side of the liver resection does not impact the perioperative and long term outcomes in patients undergoing curative-intent resection. A surgical strategy should be planned based on the possibility of achieving $\mathrm{R} 0$ resection with the confirmed negative margin of tissue by histopathologic test. The 5 -year overall survival rates after radical tumor resection varied from $20 \%$ to even $40 \%[37,38]$. Radical operative treatment is proposed even for locally advanced tumor stages. The criteria for resectability include absence of liver metastases, absence of carcinomatosis, and absence of vascular invasion. Local tumor advancement plays a minor role in these considerations [39]. A critical assessment of the patient's preoperative imaging is necessary to determine tumor resectability. The advantage of T-stage over Bismuth-Corlette tumor classification for such purposes is stressed in many studies $[40,41]$. The percentage recurrence is high. The problem is that we still lack accurate noninvasive biomarkers for the diagnosis and to estimate the prognosis while evaluating patients populations. So, definitive resection, combined with adjuvant therapy to reduce the risk of recurrence should be the standard approach for selected patients. Chemotherapy medications that are used are fluorouracil, gemcitabine, and cisplatin [39-42]. If surgery is not possible, in unresectable Klatskin tumors, the patients should be treated by radiotherapy and/or chemotherapy. Low-dose chemotherapy can make the tissue more sensitive to radiation, however, radiation therapy can be used with or without low-dose chemotherapy. Gemcitabine combined with cisplatin therapy has been recognized recently as a standard treatment for unresectable Klatskin tumors $[39,40]$. In Germany, radiation 
therapy for Klatskin tumor is used after partial tumor resection. It is also used as the main treatment method for advanced stages of cancer [43]. Decompression of the biliary tract plays an important role in the treatment process. Stents should be placed by percutaneous transhepatic USG or CT guided procedures instead of standard ERCP procedure to avoid possible intrahepatic infection. However, chemotherapy is not recommended as the neoadjuvant treatment since it can delay more effective therapy possibly even by months [39, 40, 42].

The results presented in the paper correspond, to a large extent, to results presented in recent professional literature. This is because the approach to the treatment has corresponded with changing and constantly modernizing treatment methods in the leading world HPB Centers. The large sample size and long study period are certainly strengths of this study, but the analysis may exhibit some bias characteristic for studies carried out over a long time period on a large sample of patients with a very specific type of disease. Thus, localization and the extent of the malignancy could be sources of bias, especially in patients with diseases in their advanced stage, since they were diagnosed and categorized mostly by evaluation and interpretation of radiologic images. The stage of classification was just presumed in some patients with advanced tumors, and this can be biased, since it was based on the results of cytology and radiologic images. Moreover, the causal-effect relationship between procedures and a patient's long-term outcome may have given rise to a small amount of bias in the interpretation of the results. However, as regarding treatment modalities, all procedures were performed by the same highly experienced specialists, according to the same operative procedures. Subsequently, any variations in performance of the procedure caused by the individual nature of a particular specialist, were too small to generate significant differences. Therefore, we believe that the study results can be generalized due to the considerable large number of patients included in the study, followed up on for a relatively long time, but with proper caution exercised due to its limitations and bias.

\section{Conclusions}

Surgery, if radical tumor resection is possible, offers some chance for long-term survival. The effects of surgical treatment are of little consequence in the face of poor treatment outcomes of palliative patients, however. Unfortunately, the majority of hilar tumors are diagnosed in their advanced loco-regional stages. This state of affairs results from the biologic behavior of the tumor and its location.

\section{Acknowledgments}

The results presented in the study are the summary of efforts and experiences of the team from the Department of General, Transplant \& Liver Surgery, Medical University of Warsaw, in the field of treatment of hilar cholangiocarcinoma. The authors would like to show their gratitude to all surgeons and nurses of the Department for their commitment in caring for the patients during the course of this study. Ethical Approval: According to Polish, law ethical approval was not required.

Conflict of interest: none declared

\author{
Janusz Sierdziński \\ Medical University of Warsaw \\ Departament of Medical Informatics and Telemedicine \\ ul. Litewska 14/16 \\ 00-581 Warsaw, Poland \\ e-mail:jsierdzinski@wum.edu.pl
}

Received: 8 Aug 2021

Accepted: 14 Sep 2021

\section{References}

1. Sharma P, Yadav S. Demographics, tumor characteristics, treatment, and survival of patients with Klatskin tumors. Ann Gastroenterol. 2018; 31(2): 231-236, doi: 10.20524/aog.2018.0233, indexed in Pubmed: 29507471.

2. Bismuth $\mathrm{H}$, Nakache $\mathrm{R}$, Diamond T. Management strategies in resection for hilar cholangiocarcinoma. Ann Surg. 1992; 215(1): 31-38, doi: 10.1097/00000658-199201000-00005, indexed in Pubmed: 1309988.

3. Soares KC, Kamel I, Cosgrove DP, et al. Hilar cholangiocarcinoma: diagnosis, treatment options, and management. Hepatobiliary Surg Nutr. 2014; 3(1): 18-34.

4. Launois B, Reding R, Lebeau G, et al. Surgery for hilar cholangiocarcinoma: French experience in a collective survey of 552 extrahepatic bile duct cancers. J Hepatobiliary Pancreat Surg. 2000; 7(2): 128-134, doi: 10.1007/s005340050166, indexed in Pubmed: 10982604.

5. Singhal D, van Gulik TM, Gouma DJ. Palliative management of hilar cholangiocarcinoma. Surg Oncol. 2005; 14(2): 59-74, doi: 10.1016/j. suronc.2005.05.004, indexed in Pubmed: 16019208.

6. Connor S, Barron E, Redhead DN, et al. Palliation for suspected unresectable hilar cholangiocarcinoma. Eur J Surg Oncol. 2007; 33(3): 341-345, doi: 10.1016/j.ejso.2006.11.005, indexed in Pubmed: 17175127.

7. Jarnagin W, Winston C. Hilar cholangiocarcinoma: diagnosis and staging. HPB (Oxford). 2005; 7(4): 244-251, doi: 10.1080/13651820500372533, indexed in Pubmed: 18333200.

8. Choi JY, Kim MJ, Lee JM, et al. Magnetic resonance cholangiography: comparison of two- and three-dimensional sequences for assessment of malignant biliary obstruction. Eur Radiol. 2008; 18(1): 78-86, doi: 10.1007/s00330-007-0670-6, indexed in Pubmed: 18236046.

9. Strongin $\mathrm{A}$, Singh $\mathrm{H}$, Eloubeidi $\mathrm{MA}$, et al. Role of endoscopic ultrasonography in the evaluation of extrahepatic cholangiocarcinoma. Endosc Ultrasound. 2013;2(2):71-76, doi: 10.4103/2303-9027.117690, indexed in Pubmed: 24949368.

10. Aloia TA, Charnsangavej C, Faria S, et al. High-resolution computed tomography accurately predicts resectability in hilar cholangiocarcinoma. Am J Surg. 2007; 193(6): 702-706, doi: 10.1016/j.amjsurg.2006.10.024, indexed in Pubmed: 17512280.

11. Cannon RM, Brock G, Buell JF. Surgical resection for hilar cholangiocarcinoma: experience improves resectability. HPB (Oxford). 2012; 14(2): 142-149, doi: 10.1111/j.1477-2574.2011.00419.x, indexed in Pubmed: 22221577.

12. de Jong MC, Marques $\mathrm{H}$, Clary BM, et al. The impact of portal vein resection on outcomes for hilar cholangiocarcinoma: a multi-institutional analysis of 305 cases. Cancer. 2012; 118(19): 4737-4747, doi: 10.1002/ cncr.27492, indexed in Pubmed: 22415526.

13. Washburn WK, Lewis WD, Jenkins RL. Aggressive surgical resection for cholangiocarcinoma. Arch Surg. 1995; 130(3): 270-276, doi: 10.1001/ archsurg.1995.01430030040006, indexed in Pubmed: 7534059.

14. Nimura Y, Kamiya J, Kondo S, et al. Aggressive preoperative management and extended surgery for hilar cholangiocarcinoma: Nagoya experience. J Hepatobiliary Pancreat Surg. 2000; 7(2): 155-162, doi: 10.1007/s005340050170, indexed in Pubmed: 10982608.

15. Neuhaus $\mathrm{P}$, Jonas $\mathrm{S}$, Bechstein WO, et al. Extended resections for hilar cholangiocarcinoma. Ann Surg. 1999; 230(6): 808-18; discussion 819, doi: 10.1097/00000658-199912000-00010, indexed in Pubmed: 10615936.

16. Mansour J, Aloia T, Crane C, et al. Hilar Cholangiocarcinoma: expert consensus statement. HPB. 2015; 17(8): 691-699, doi: 10.1111/hpb.12450. 
17. Cho MS, Kim SH, Park SW, et al. Surgical outcomes and predicting factors of curative resection in patients with hilar cholangiocarcinoma: 10-year single-institution experience. J Gastrointest Surg. 2012; 16(9): 1672-1679, doi: 10.1007/s11605-012-1960-0, indexed in Pubmed: 22798185.

18. Nuzzo G, Giuliante F, Ardito F, et al. Italian Chapter of the International Hepato-Pancreato-Biliary Association. Improvement in perioperative and long-term outcome after surgical treatment of hilar cholangiocarcinoma: results of an Italian multicenter analysis of 440 patients. Arch Surg. 2012; 147(1): 26-34, doi: 10.1001/archsurg.2011.771, indexed in Pubmed: 22250108.

19. van Gulik TM, Ruys AT, Busch ORC, et al. Extent of liver resection for hilar cholangiocarcinoma (Klatskin tumor): how much is enough? Dig Surg. 2011; 28(2): 141-147, doi: 10.1159/000323825, indexed in Pubmed: 21540600.

20. Zhang BH, Cheng QB, Luo XJ, et al. Surgical therapy for hiliar cholangiocarcinoma: analysis of 198 cases. Hepatobiliary Pancreat Dis Int. 2006; 5(2): 278-282, indexed in Pubmed: 16698591.

21. Baton O, Azoulay D, Adam DV, et al. Major hepatectomy for hilar cholangiocarcinoma type 3 and 4: prognostic factors and longterm outcomes. J Am Coll Surg. 2007; 204(2): 250-260, doi: 10.1016/j.jamcollsurg.2006.10.028, indexed in Pubmed: 17254929.

22. Seyama Y, Kubota K, Sano K, et al. Long-term outcome of extended hemihepatectomy for hilar bile duct cancer with no mortality and high survival rate. Ann Surg. 2003; 238(1): 73-83, doi: 10.1097/01. SLA.0000074960.55004.72, indexed in Pubmed: 12832968.

23. Matull WR, Dhar DK, Ayaru $L$, et al. Ro but not $R 1 / R 2$ resection is associated with better survival than palliative photodynamic therapy in biliary tract cancer. Liver Int. 2011; 31(1): 99-107, doi: 10.1111/j.1478-3231.2010.02345.x, indexed in Pubmed: 20846273.

24. Eckel F, Schmid RM, Eckel F, et al. Chemotherapy in advanced biliary tract carcinoma: a pooled analysis of clinical trials. Br J Cancer. 2007; 96(6): 896-902, doi: 10.1038/sj.bjc.6603648, indexed in Pubmed: 17325704.

25. Miao X, Pei D, Wen Yu, et al. Prognostic Value of Bismuth Typing and Modified T-stage in Hilar Cholangiocarcinoma. Cancer Translational Medicine. 2015; 1(1): 1, doi: 10.4103/2395-3977.151467.

26. Rea DJ, Munoz-Juarez M, Farnell MB, et al. Major hepatic resection for hilar cholangiocarcinoma: analysis of 46 patients. Arch Surg. 2004; 139(5): 514-23; discussion 523, doi: 10.1001/archsurg.139.5.514, indexed in Pubmed: 15136352

27. Cassani LS, Chouhan J, Chan C, et al. Biliary Decompression in Perihilar Cholangiocarcinoma Improves Survival: A Single-Center Retrospective Analysis. Dig Dis Sci. 2019; 64(2): 561-569, doi: 10.1007/s10620-0185277-z, indexed in Pubmed: 30238201.

28. Teng F, Xian YT, Lin J, et al. Comparison of Unilateral With Bilateral Metal Stenting for Malignant Hilar Biliary Obstruction. Surg Laparosc Endosc Percutan Tech. 2019; 29(1): 43-48, doi: 10.1097/SLE.0000000000000594, indexed in Pubmed: 30418421

29. Mansfield SD, Barakat O, Charnley RM, et al. Management of hilar cholangiocarcinoma in the North of England: pathology, treatment, and outcome. World J Gastroenterol. 2005; 11(48): 7625-7630, doi: 10.3748/ wjg.v11.i48.7625, indexed in Pubmed: 16437689.

30. Zheng-Rong L, Hai-Bo Y, Xin C, et al. Resection and drainage of hilar cholangiocarcinoma: an 11-year experience of a single center in mainland China. Am Surg. 2011; 77(5): 627-633, indexed in Pubmed: 21679599.

31. Szymańska D, Durczyński A, Strzelczyk J. Hepatico-jejunostomia obwodowa; alternatywna metoda leczenia paliatywnego nieresekcyjnych guzów wnęki Wątroby. Doniesienie wstępne. Nowotwory J Oncology. 2009; 70(2): 188-193.

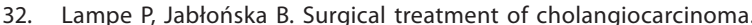
Postępy Nauk Medycznych. 2011; 1: 16-22.

33. Palczewski P, Cieszanowski A, Gołębiowski M. State of the art imagine of Klatskin tumor. Polish J Radiology. 2005; 70(2): 69-77.

34. Janczak D, Wierasko A, Kabziński P, et al. Implantation of plastic and metal stents to biliary tract in obstructive jaundice in material of Surgery Department of 4th Military Clinical Hospital in Wroclaw. Polim Med. 2013; 43(1): 5-9, indexed in Pubmed: 23808190.

35. Jeziorski KG. Współczesne możliwości chemioterapii nowotworów złośliwych wątroby i dróg żółciowych zewnątrzwątrobowych. Nowotwory J Oncology. 2007; 52(1): 9-13.

36. Jassem J, Duchnowska R, Kawecki A, et al. Post-treatment surveillance in most common solid malignancies in adults. Nowotwory J Oncology. 2014; 64(5): 415-435, doi: 10.5603/NJO.2014.0070.

37. Jo HS, Kim DS, Yu YD, et al. Right-side versus left-side hepatectomy for the treatment of hilar cholangiocarcinoma: a comparative study. World J Surg Oncol. 2020; 18(1): 3, doi: 10.1186/s12957-019-1779-1, indexed in Pubmed: 31901228.

38. Lidsky ME, Jarnagin WR. Surgical management of hilar cholangiocarcinoma at Memorial Sloan Kettering Cancer Center. Ann Gastroenterol Surg. 2018; 2(4): 304-312, doi: 10.1002/ags3.12181, indexed in Pubmed: 30003193.

39. Nickloes T, Reed B, Mack LaMar O. Bile duct tumors: Treatment \& management. Medscape, Drugs \& Diseases. In: General Surgery 2020. Updated: Apr 20

40. Dondossola D, Ghidini M, Grossi F, et al. Practical review for diagnosis and clinical management of perihilar cholangiocarcinoma. World J Gastroenterol. 2020; 26(25): 3542-3561, doi: 10.3748/wjg.v26. i25.3542, indexed in Pubmed: 32742125.

41. Mizuno T, Ebata T, Nagino M. Advanced hilar cholangiocarcinoma: An aggressive surgical approach for the treatment of advanced hilar cholangiocarcinoma: Perioperative management, extended procedures, and multidisciplinary approaches. Surg Oncol. 2020; 33: 201-206, doi: 10.1016/j.suronc.2019.07.002, indexed in Pubmed: 31301935.

42. Banales JM, Marin JJG, Lamarca A, et al. Cholangiocarcinoma 2020: the next horizon in mechanisms and management. Nat Rev Gastroenterol Hepatol. 2020; 17(9): 557-588, doi: 10.1038/s41575-020-0310-z, indexed in Pubmed: 32606456.

43. Ivanisova N, Solovey A. Klatskin tumor: treatment of bile duct cancer in Germany. Booking Health GmbH > Diagnosis \& treatment 2021. https://bookinghealth.com 